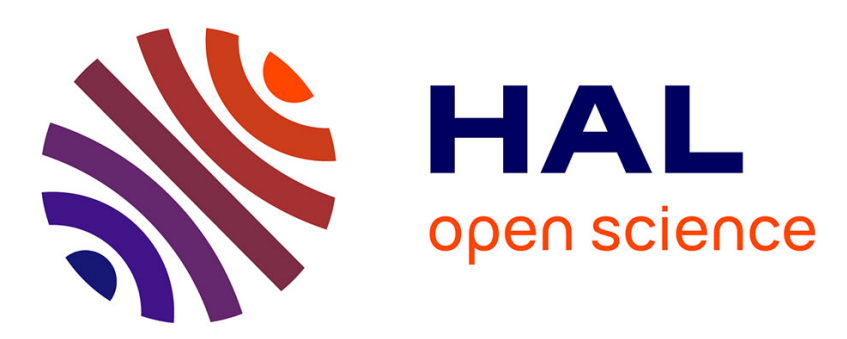

\title{
Different experimental ways to minimize the preforming defects of multi-layered interlock dry fabric
}

\author{
Anwar Shanwan, Samir Allaoui
}

\section{To cite this version:}

Anwar Shanwan, Samir Allaoui. Different experimental ways to minimize the preforming defects of multi-layered interlock dry fabric. International Journal of Material Forming, 2018, 12 (1), pp.69-78. 10.1007/s12289-018-1407-6 . hal-01763133

\section{HAL Id: hal-01763133 \\ https://hal.science/hal-01763133}

Submitted on 10 Apr 2018

HAL is a multi-disciplinary open access archive for the deposit and dissemination of scientific research documents, whether they are published or not. The documents may come from teaching and research institutions in France or abroad, or from public or private research centers.
L'archive ouverte pluridisciplinaire HAL, est destinée au dépôt et à la diffusion de documents scientifiques de niveau recherche, publiés ou non, émanant des établissements d'enseignement et de recherche français ou étrangers, des laboratoires publics ou privés. 


\title{
Different experimental ways to minimize the preforming defects of multi- layered interlock dry fabric.
}

\author{
A. Shanwan ${ }^{1}$, S. Allaoui ${ }^{1}$ \\ ${ }^{1}$ Univ. Orléans, Univ. Tours, INSA CVL, LaMé, EA 7494, F-45072 Orléans, France.
}

Corresponding author: $\underline{\text { samir.allaoui@univ-orleans.fr }}$

Keywords: Fabrics/textiles, Lamina/ply, Preform, Defects

\begin{abstract}
:
This study presents a strategy to improve the quality of a dry fabric's preforms. Preforming tests were realized with one and two-layers of interlock carbone fabric at different configurations. Initial results led to preforms with several defects. For one-layer preforming, a new blank holder geometry and an increase of the pressure applied on the fabric allowed to improve the quality of the preforms. On the other hand, for two-layer preforming, the insertion of a mat fabric in the interface of the two preformed layers allowed to decrease the friction and to improve the preforms quality, significantly.
\end{abstract}

\section{INTRODUCTION}

Long fiber-reinforced composites are widely used in various industries, especially in transportation, because it gives the possibility to reach a light final product. Liquid Composite Molding (LCM) processes are among the most interesting manufacturing processes to produce composite parts with complex geometry, because they offer a very interesting compromise in terms of repeatability. The first stage of this process (preforming) is delicate because there are several deformation mechanisms, which are very different from those of steel sheets stamping [1].

The quality of preforms of double curved geometries depends on several parameters, such as: punch geometry, relative orientation of punch/fabric-layers and blank-holders pressure. These parameters play a major role on the quality of the final shape in term of defects appearance [2]. 
Predicting of preforms quality, for a given shape with a given fabric, and subsequently, the defects that may appear, can be verified by using of finite element simulations [3-8] or experimental studies [2, 8-13]. In addition, during the manufacturing of composite parts, several layers of fabric are stacked together. As these layers (sheets) are not being interdependent, they have different behaviors and can relatively slide, each to other. By this way, an inter-ply friction is generated between them. Several studies showed that the preform quality depends highly on the inter-ply friction, which takes place between the superposed layers during forming [14-19]. Moreover, the friction effect is more severe in case of dry woven fabrics, due to shocks between the overhanging yarns of the superposed layers [20]. A recent study highlighted the influence and criticality of interply friction according to sequence of layers stacking, especially when the inter-ply sliding is greater than the unit cell length of the fabric [15].

The aim of this study is to improve the quality of preforms of dry woven fabrics, by reducing or eliminating the defects via two criteria: the definition of the best process parameters and the second one is the reduction of inter-ply friction by improving the interface between the layers.

\section{MATERIAL AND METHODS}

Tests presented in this paper are performed on a commercial composite woven reinforcement, which is a powdered interlock fabric, denoted Hexcel G1151®, with a surface weight of $630 \mathrm{~g} / \mathrm{m}^{2}$. This fabric is composed of around $\approx 7.5$ yarns $/ \mathrm{cm}$ in warp and weft directions. The unit cell of G1151® consists of 6 warp yarns and 15 weft yarns distributed on three levels. In situ, the average yarn width is about $2 \mathrm{~mm}$ for warp and $3 \mathrm{~mm}$ for weft. A specific forming device, developed at LaMé laboratory was used to perform the shaping tests [1,9]. This device is equipped with two CCD cameras to track the yarns position and measure the plane shear of the reinforcement. During preforming process, there is a complex relationship between three parameters: fabric mechanical properties, forming process parameters and punch (part) shape. This paper aims to improve the preforming quality of dry interlock fabric and to avoid, as possible as, the appearance of defects during preforming process on a given shape. To study a wide range of defects with a maximum of amplitudes, our tests were carried-out by means of a highly non-expandable and double curved form (prismatic punch) having a triple point and small curvature radii (10mm). The punch dimensions are shown in Figure $1[2,15]$. 
The different preforming configurations, presented in this study, are illustrated in Figure 2 [2, 15], where eight blank-holders are used around the preform to apply a pressure of 0.15 bar on the fabric (Figure 2, a). The tests were done with a punch speed of $30 \mathrm{~mm} / \mathrm{min}$.

For both monolayer and two-layers preforming tests, the same experimental conditions are used. In case of mono-layer preforming, several orientations of ply/punch are also used $\left(\alpha^{\circ}: 0^{\circ}, 30^{\circ}, 45^{\circ}\right.$, $60^{\circ}$ and $90^{\circ}$ ). The $0^{\circ}$ orientation, which is considered as reference configuration (Figure 2.a), means that the weft and warp directions of the stacked layers are parallels to the lateral edges of the punch faces. In case of two-layers performing, the tests are conducted by stacking one of layers at $0^{\circ}$ and the other-one at $\alpha^{\circ}$ (Figure 2.b), with several configurations such as : $0^{\circ} / 0^{\circ}, 0^{\circ} / 90^{\circ}, 0^{\circ} / 45^{\circ}, 45^{\circ} / 0^{\circ}$, etc. Herein, $\alpha^{\circ} / 0^{\circ}$ means that the upper layer is oriented at $\alpha^{\circ}$ and the lower one at $0^{\circ}$.

\section{RESULTS AND DISCUSSIONS}

For monolayer preforming configuration, the first tests were carried-out with a monolayer oriented at $0^{\circ}$ (reference configuration) and at the same optimal conditions, found in a previous study [2] for the same type of fabric. Preforming tests showed a good preforms quality at macroscopic level (Figure 3.a) since the preform useful area does not have wrinkles defect. Nevertheless, at mesoscopic level, 'buckle'" defects occur on the faces and the edges of prismatic preform where yarns are subjected to in plane bending. Subsequently, these yarns undergo an outof-plane buckling, so that the weaving pattern is not respected for a long time. In terms of shear angles, the maximal values are reached at the bottom corners of the preforms $\left(50^{\circ}\right.$ and $\left.55^{\circ}\right)$. These values are close to the interlock fabric-locking angle. On the other hand, no wrinkles defects occurred in the preform useful area due to the coupling between shear and tension, which can delay the onset of wrinkles when the tension applied on fabric increases [2, 21, 22].

A comparison between the $0^{\circ}$ configuration and the others of $90^{\circ}, 0^{\circ} / 0^{\circ}, 0^{\circ} / 90^{\circ}, 90^{\circ} / 0^{\circ}$ and $90^{\circ} / 90^{\circ}$ shows the same results with the same defects (Figure 3.b). In fact, in all of these cases, the relative orientation between yarn networks and the punch remains unchangeable, which confirm the effect of the relative position of punch/fabric. The only difference between the $0^{\circ}$ and $90^{\circ}$ preforms is the inverting of the position of weft and warp networks.

\subsection{Oriented monolayer preforming tests}


The preforms obtained by oriented monolayers $\left(\alpha \neq 0^{\circ}\right.$ and $\left.\alpha \neq 90^{\circ}\right)$ show more extensive defects than the above-mentioned case $\left(0^{\circ}\right.$ and $\left.90^{\circ}\right)$ although the shear angle values remain in the same scope obtained in the case of reference configurations.

Despite the small shear angles, wrinkles occur at the useful area, as illustrated at zone 1 of the Figure 4 (case of monolayer oriented at $30^{\circ}$ ). As shown in this figure, wrinkles appear on two opposite corners of the preform where the observed shear angles are low $\left(22^{\circ}\right)$. Moreover, there are no wrinkles defects on the frontal face (area 3), where high shear angles are observed $\left(49^{\circ}\right)$. In addition, "buckle" defects are also observed in this preform (areas 2) and are located at different emplacements by comparison with those obtained at $0^{\circ}$ monolayer orientation. These "buckle" defects are almost due to bending stresses applied on yarns during preforming. These observations correspond to those obtained in previous studies $[2,15]$ and confirm the significant effect of the relative orientation of punch/ply on the preform quality for complex geometries.

Subsequently, in the case of oriented configurations $\left(0^{\circ}<\alpha<90^{\circ}\right)$, the preforms quality is not acceptable. In fact, a bad preforms quality leads to aesthetic problems and non-respect of the dimensional specifications. In addition, these defects may have an effect on the mechanical performances of the final part [23, 24]. Therefore, the preforms quality needs to be improved.

The improvements can be achieved by different strategies like : substitution of fabric by another one with a better formability, changing of manufacturing process, applying of best manufacturing process parameters, and/or modifying of ply orientations and parts geometry, etc. From an industrial point of view, certain strategies could be costly and/or time-consuming (change of process, change of reinforcement).

However, some parameters are often set by the technical specifications of the part (such as: ply orientations, geometry, type of reinforcement, etc...). Furthermore, the modifying of such parameters can affect the entire project of system in which the part would evolve. Thus, the most interesting strategy to adopt is to modify the parameters that do not affect the specifications of the part. It will be possible, for example, to improve the preforms quality by optimizing of the process parameters.

Hence, a new strategy depending on modifying of some process parameters, such as the blank holder's pressure and their geometry, was adopted. On the other hand, the other parameters like the orientation of layers, the punch geometry and the type of fabric, remain fixed. Preforming tests are held on oriented layers, a change was applied on two parameters: blank holder's pressure and 
blank holder's geometry. This change was applied separately in order to analyze the results and define which parameter is more important than the others on the preforms quality.

The tests showed that the increasing of tensile force applied on the yarn's networks, which is obtained by increasing of blank holder pressure, leads to a delay on the onset of wrinkles or to avoid them $[2,21,22]$. Therefore, the pressure was firstly increased up to 0.2 bars only on the two square blank holders located on the opposite corners B\&D, where wrinkles defect appear (Figure 4). The maximal value of the pressure was defined by the capacity of the compressed air system. The obtained results show that the wrinkles remain on the preform but their amplitude is slightly decreased (Figure 5). In addition, the shear angles did not change on the preform areas compared to the case where the pressure applied on fabric is 0.15 bar (figure 4 ).

The tests showed that the increase in the blank holders' pressure did not allow avoiding of wrinkles completely. Hence, an adapted blank holder's geometry was suggested to improve the preforms quality [25]. A single blank holder surrounding the preform, which eliminates the gaps present in the initial configuration, has been used to replace the eight individual ones.

Thus, new tests were performed by using of this geometry with a pressure of 0.15 bars. As shown in Figure 6, the obtained preform has a better quality because there is a higher decrease in wrinkles amplitude than the one obtained by pressure increasing. It means that the effect of blank holder geometry on the preform quality is more significant than the effect of pressure because the blank holder controls the force application and its distribution on the yarns. However, the change of blank-holders geometry did not allow the elimination of wrinkles completely.

For this reason, a third solution, depending on combining of the two previous strategies was used in order to improve the quality of the preforms (pressure of 0.20 bars + single blank holder). In this case, a good quality was obtained without any wrinkles defect, as shown in Figure 7. Subsequently, the combining of several optimized parameters can leads to the avoiding of wrinkle defects.

On the other hand, buckles defects remain appeared in the useful area in spite of the previous suggested solutions. The extent of the region of these defects and their amplitude are almost identical. Consequently, "buckle" defects can not be avoided completely by the strategy used in this study. In fact, this defect is generated by in plane bending of yarns that leads to their out of plane buckling promoted by the fact that the fibers are continuous and not bonded together. To avoid this defect completely, it may be possible to change the nature of yarns and/or their geometry. This solution is sometimes possible with natural yarns [25], which are close to a homogeneous 
material because the fibers are bonded between them, but it is difficult or impossible to be achieved in the case of carbon and glass yarns.

As a conclusion of this part, the relative orientation of punch/layer has a significant influence on the preform quality whereas the optimizing of process parameters (blank holder geometry and/or applied pressure) can lead to further improvements in preforms quality. In addition, it is highlighted that the blank holder geometry has more significant effect than the tensile applied on the yarn networks. Finally, the combination of these two solutions led to better results. Moreover, the two improvements do not have an important influence on the mesoscopic defects (buckles) because they have no act on the mechanisms involved in the appearance of these defects.

\subsection{Multilayers preforming tests}

The same approach used in monolayer tests was applied for two-layers preforming tests. In this paragraph, we present the results of $45^{\circ} / 0^{\circ}$ preforms $\left(45^{\circ} / 0^{\circ}\right.$ means that the oriented layer is the external one in the stacking order). The $45^{\circ} / 0^{\circ}$ stacking sequence was chosen for two reasons: firstly, because it is more prone to have defects than the $0^{\circ} / 45^{\circ}$ configuration [15] and secondly, it enables to observe and make the required measurements on the outer layer $\left(45^{\circ}\right)$, in order to be compared with a monolayer, preformed at $45^{\circ}$.

The preforming results of $45^{\circ} / 0^{\circ}$ stacking sequence, obtained with the same initial process parameters, show more numerous defects than $45^{\circ}$ monolayer preform, and thus, a bad quality is obtained as shown in Figure 8. The type and location of these defects remain the same of those of $45^{\circ}$ monolayer configuration but their amplitude and their quantities are significantly higher, whereas the shear angle values remain unchanged relatively (Figure 8). In fact, the bad quality is attributed to inter-ply friction as it has been highlighted and demonstrated in previous study [15].

The inter-ply friction lead to the appearance of additional wrinkles in the center of the frontal face of two-layer preforms, where there are highest shear angles. Moreover, when compared with $30^{\circ}$ and $30^{\circ} / 0^{\circ}$ preforms, the configurations of $45^{\circ}$ and $45 / 0^{\circ}$ show more numerous defects and other additional types of defects also, like the weave pattern heterogeneity (Figure 4 and Figure 8 ). The 
increase in type and amplitude of defects is induced by the effect of the punch/layer relative orientation.

To improve the quality of $45^{\circ} / 0^{\circ}$ preforms, the same strategy, used for oriented monolayers, was applied. Thus, draping tests were conducted firstly with an increasing in the blank holder's pressure, then by using the new blank holder geometry and finally by combining of the two solutions together. The obtained results show an improvement in the two-ply preforms quality with the same trend observed for monolayer preforms, i.e., the use of the new blank holder geometry gives better results than the increase in pressure (Figure 9). When the two solutions are used together, their effect was combined and thus a greater improvement was obtained (Figure 10). However, defects remain always on the preform in spite of these improvements. Subsequently, the combination of these two solutions did not enable to avoid wrinkles completely.

In fact, in the $45^{\circ} / 0^{\circ}$ configuration, there is an interface between the two stacked layers, which plays a major role on the preform quality. It has been showed in a previous study that the amount and the amplitude of defects increase because of inter-ply friction, caused by the relative sliding between layers [15]. The fabric/fabric friction behavior is governed by shock phenomenon occurring between transverse overhanging yarns of each ply, which leads to signal variation with high amplitudes due to the high tangential forces generated by shocks (Figure 11). The tangential forces hampers the sliding of the plies locally and lead to an increase in defects appearance and amplitude. The inter-ply friction effect is significant when inter-ply sliding is larger than the fabric's unit cell length. In the case of $45^{\circ} / 0^{\circ}$, the measured sliding distance can reach more than $70 \mathrm{~mm}$ while the unit cell length is about $8 \mathrm{~mm}$.

To avoid the overhanging yarns shocks, it is necessary to reduce the inter-ply sliding or to decrease the inter-ply friction. The reduction of sliding distance remains difficult to be achieved because it depends on both relative positions of ply/ply and punch/ply.

However, it is possible to reduce the global ply/ply friction behavior by making the dynamic friction smoother. For this aim, avoiding or reduction of shock phenomenon, occurring between yarns, is necessary. This can be achieved by several solutions that require modifying of: crimp, fabric meso-architecture, yarns shape and/or their material, surface treatment, etc. These improvements will therefore induce a change of reinforcement or its characteristics, whereas it is sometimes not possible to change them according to technical specifications. 
To overcome this problem, we proposed the inserting of an intermediate mat reinforcement layer between the two performed plies. This solution does not need to change the fabric or change its characteristics (crimp, meso-architecture, ...). As the mat is not a woven fabric, there is no shocks, which take place between the different plies of fabric. Indeed, it is evident that the mat insertion induces a modification of the stack, and therefore, a modification of the mechanical performances and of stage following stage of LCM processes (resin injection/infusion), which have to be considered.

To verify this assumption, friction tests were conducted on fabric/mat in order to compare their results with those of fabric/fabric. Commercial glass mat, with an areal weight of $300 \mathrm{gr} / \mathrm{m}^{2}$, was used for this study. These tests were done by means of experimental test bench, which was developed at LaMé laboratory of Orleans University [26]. The bench working principle depends on the sliding of two plans surfaces (Figure 12). A normal force $F_{N}$ is applied on the upper sample, which is fixe and connected to a tensile force sensor. The lower sample could be moved horizontally so that it generates a tangential force, which can be measured by the sensor. Fabric/mat friction tests were carried-out in warp and weft directions according to the experimental conditions illustrated on table 1.

The obtained fabric/mat friction behaviors are presented on Figure 13, where we observe smoother dynamic friction behaviors in comparison with behavior of interlock/interlock (Figure 11 and Figure 13). This means that there are no yarn's shocks during the relative sliding of plies. In addition, the average values of the dynamic friction coefficient for fabric/mat are 0.25 in wrap direction and 0.35 in weft direction. These values are reduced at least to the half in comparison with fabric/fabric case, where the friction coefficient is around 0.61 .

Theses results confirm our hypothesis and, therefore, could leads to an improvement of the preform quality of two stacked layers. To verify this fact, preforming tests were carried out after inserting of glass mat between the two layers of $45^{\circ} 0^{\circ}$ configuration with 0.15 bars pressure applied by the single blank holder, which surrounds the preform (Erreur ! Source du renvoi introuvable.). The Figure 15 shows the positive effect of this strategy because the wrinkles defects have decreased significantly in comparison with the case illustrated in Figure 10. The remaining defects have a low amplitude, which could be negligible with comparison to the initial configuration. 
Consequently, defects amplitude is highly reduced thanks to the mat using. The observed improvements were specially been observed at B and D corners (Figure 15). In this case, the global amelioration is due to two reasons:

The mat prevents any direct contact between overhanging yarns of G1151 ${ }^{\circledast}$ preformed layers, i.e., there are no shocks between the yarns of the two layers, even if the sliding between layers is higher than the fabric's unit cell length. Subsequently, the using of an intermediate layer (glass mat) has an important role on the stabilization of friction coefficient. In addition, stress is also reduced during the sliding between performed layers. The mat allows a smooth friction during the inter-ply sliding, and so, the friction coefficient is reduced. Hence, wrinkles and buckles amplitudes are enormously reduced.

These results highlight the importance of the intermediate mat layer in the reduction of friction coefficient and consequently in the reduction of the amplitude of defects. In addition, the using of an intermediate mat layer ensures a stabilization in friction coefficient variation during the sliding, i.e. the variation amplitude of friction coefficient in the case of mat/fabric fiction was reduced to a quart comparing to the case of fabric/fabric friction.

Finally, it can be concluded that the combining of the three previous solutions (new blank-holders geometry, pressure increasing and mat using) allows an enormous reduction in the defects appearance and in their amplitude. Thanks to combining of these solutions, it was practically possible to avoid the defects appearance in the preform useful area, especially, wrinkles defects.

Nevertheless, whichever the improvement level, the defects remain even with small amplitude. For this reason, we decided to combine all previous improvements solutions with the last improvement, which is the use of compaction effect between layers. Indeed, it has been shown that if the layer subjected to defects was at the inner position, relatively to the punch, the outer ply applies a compaction effect that leads to decrease in defects [15] (case of configuration $0^{\circ} / 45^{\circ}$ ). This configuration is more interesting because in conventional laminates, a ply oriented at $0^{\circ}$ or $90^{\circ}$ is often placed outside the stacking, which make this improvement viable industrially. Subsequently, preforming tests were done by combining of the four following solutions together:

- Use of a new blanks-holders geometry;

- Use of the optimal pressure value ( 0,15 bars);

- Use of intermediate mat layer between the preformed fabric's layers; 
- Laying the oriented ply below the non-oriented one, i.e., using the $0 \% / 45^{\circ}$ stacking sequence.

Indeed, as shown in Figure 16, wrinkles defects were completely disappeared, thanks to combining of the four mentioned solutions. Only the buckles defect still on the preform, as shown at the central face of the preform (Figure 16).

Finally, each one of these four improvement solutions was applied alone, in this experimental study, in order to classify them according to their influence on the defects appearance. The defects and the preform quality obtained after applying of each solution were compared quantitatively and qualitatively. The results are summarized on table 2 . The sign (+) means that the solution has a positive effect to avoid the considered defect while the (-) sign means a bad effect.

According to these results, the improvement solutions can be classified according to their importance, from the more significant to the smallest one, as follows:

1) Reduction and stabilization of dynamic friction coefficient (by introducing of intermediate mat between the layers);

2) Adapted blank-holders' geometry number;

3) Laying the oriented layer below the non-oriented one;

4) Applying a tensile, through the blank holder pressure, on the yarns' networks.

\section{CONCLUSION}

This study presents a strategy to improve the quality of dry complex preforms. The results showed that the inter-ply friction and the relative orientation between layers and the punch influence the preforms quality significantly by inducing numerous defects with large amplitudes and extent. The modifying of the blank holder geometry and the increase of their pressure enabled to improve the quality of the monolayer preforms. The changes in these parameters allowed avoiding wrinkles in the monolayer preforms. On the other hand, they did not show significant improvements in the two-layer preforms quality since the inter-ply friction, occurring during the preforming of multi-layers, affects the defects appearance hugely.

The reduction of the inter-ply friction can be achieved by several solutions; the majority of them induces a change of the reinforcement or its characteristics, which is sometimes not possible, according to technical specifications of a composite part. The better solution to be proposed is to insert a mat fabric between the preformed layers. This one allow the decreasing of the number and 
amplitude of wrinkles significantly. However, this modification in the stack has to be considered, as it will induce a modification in the mechanical performance of the material and also of stage following stage of LCM processes (resin injection/infusion).

The obtained results showed that the inter-ply friction is the first and the most important parameter, which influences the defects appearance. Then, the blank-holders geometry is considered as the second parameter according to its importance. Next, the compaction between layers and finally the tensile applied on the yarns networks. In conclusion, suitable technical solutions should be applied to improve the friction during the shaping of dry reinforcements, in order to improve the preforms quality, which is hugely affected by the friction between layers.

\section{REFERENCES}

1. Allaoui S., Launay J., Soulat D., Chatel S., Experimental tool of woven reinforcement forming International Journal of Material Forming, 1960-6214 (Online), Category Symposium MS12: Composites Forming, (2008).

2. S. Allaoui, G. Hivet, D. Soulat, A. Wendling, P. Ouagne, S. Chatel "Experimental preforming of highly double curved shapes with a case corner using an interlock reinforcement", International Journal of Material Forming, vol 7(2), 155-165, (2014).

3. P. Boisse, N. Hamila, A. Madeo, "Modelling the development of defects during composite reinforcements and prepreg forming", Philosophical Transactions of The Royal Society A Mathematical Physical and Engineering Sciences, July 2016 DOI: 10.1098/rsta.2015.0269.

4. R.H.W. ten Thije, R. Akkerman, and J. Huétink. "Large deformation simulation of anisotropic material using an updated lagrangian finite element method". Computer Methods in Applied Mechanics and Engineering, vol 196(33-34), 3141-3150, (2007).

5. Farbod Nosrat Nezami, Thomas Gereke, Chokri Cherif, "Analyses of interaction mechanisms during forming of multilayer carbon woven fabrics for composite applications", Composites Part A, Volume 84, p406-416, 2016.

6. Farbod Nosrat Nezami, Thomas Gereke, Chokri Cherif, "Active forming manipulation of composite reinforcements for the suppression of forming defects", Composite Part A, Volume 99, pp94-101, 2017. 
7. N. Hamila and P. Boisse "A meso macro three node finite element for draping of textile composite performs". Applied Composite Materials, vol 14, 235-250, (2007).

8. S. Allaoui, P. Boisse, S. Chatel, N. Hamila, G. Hivet, D. Soulat, E. Vidal-Salle, "Experimental and numerical analyses of textile reinforcement forming of a tetrahedral shape", Composite Part A, Vol 42 (6), 612-622, (2011).

9. D. Soulat, S. Allaoui, S. Chatel, «Experimental device for the performing step of the RTM process», International Journal of Material Forming, Vol 2 (1), 181-184, (2009).

10. Vanclooster K, Lomov SV, Verpoest I., " Experimental validation of forming simulations of fabric reinforced polymers using an unsymmetrical mould configuration", Composites A, Vol,40(4), 530-539, (2009).

11. S.Chen, O.P.L.McGregor, L.T.Harper, A.EndruweitN., A.Warrior, "Defect formation during preforming of a bi-axial non-crimp fabric with a pillar stitch pattern", Composites Part A, Volume 91 (1), pp156-167, (2016).

12. James S.Lightfoot, Michael R.Wisnom, KevinPotter, "Defects in woven preforms: Formation mechanisms and the effects of laminate design and layup protocol", Composites Part A, Volume 51,pp99-107, (2013)

13. Ling Shan Liu, Peng Wang, Xavier Legrand, Damien Soulat, "Investigation of mechanical properties of tufted composites: Influence of tuft length through the thickness reinforcement”, Composite structures, Volume 172, pp21-228, 2017.

14. S. Bel, N. Hamila, P. Boisse, F. Dumont, "Finite element model for NCF composite reinforcement preforming: Importance of inter-ply sliding”. Composites Part A, vol 43, 2269_ 2277, (2012).

15. S. Allaoui, C. Cellard, G. Hivet, "Effect of inter-ply sliding on the quality of multilayer interlock dry fabric preforms" Composite Part A, vol68, 336-345, (2015). 
16. R.H.W. ten Thije, R. Akkerman, "A multi-layer triangular membrane finite element for the forming simulation of laminated composites", Composites Part A, vol 40, 739-753, (2009).

17. K. Vanclooster, S.V. Lomov and I. Verpoest, "Simulation of multi-layered composites forming" Int J Mater Form, Vol. 3 Suppl 1, 695-698, (2010).

18. Qianqian Chen, Philippe Boisse, Chung Hae Park, Abdelghani Saouab, Joël Bréard, "Intra/inter-ply shear behaviors of continuous fiber reinforced thermoplastic composites in thermoforming processes", Composite Structures, Vol 93, 1692-1703, (2011).

19. Nahiene Hamila, Philippe Boisse, «Simulations of textile composite reinforcement draping using a new semi-discrete three node finite element”, Composites Part B, Vol 39, 999-1010, (2008).

20. S. Allaoui, G. Hivet, A. Wendling, P. Ouagne, Soulat, "Influence of the dry woven fabrics meso-structure on fabric/fabric contact behavior". Journal of Composite Materials, Vol 46(6), 627-639, (2012).

21. Launay J, Hivet G, Duong AV, Boisse P. "Experimental analysis of the influence of tensions on in plane shear behaviour of woven composite reinforcements". Compos Sci Technol, vol 68(2), 506-15, (2008.)

22. Harrison P, Abdiwi F, Guo Z, Potluri P, Yu WR. "Characterising the shear-tension coupling and wrinkling behaviour of woven engineering fabrics". Compos A part A, vol 43(6), 903-14, (2012).

23. Susanne Hörrmann, Adi Adumitroaie, Christoph Viechtbauer, Martin Schagerl, "The effect of fiber waviness on the fatigue life of CFRP materials". International Journal of Fatigue, Volume 90, Pages 139-147 (2016).

24. C. Cruanes, A. Shanwan, S. Méo, S. Allaoui, M.-P. Deffarges, F. Lacroix, G. Hivet, "Effect of mesoscopic out-of-plane defect on the fatigue behavior of a GFRP", Mechanics of Materials, Volume 117, p214-224 (2018)

25. E. Capelle, P. Ouagne, D. Soulat, D. Duriatti, "Complex shape forming of flax woven fabrics: Design of specific blank-holder shapes to prevent defects", Composites Part B, Volume 62, p 29-36, (2014).

26. G. Hivet, S. Allaoui, B.T. Cam, P. Ouagne, D. Soulat, "Design and potentiality of an apparatus for measuring yarn/yarn and fabric/fabric friction”, Experimental Mechanics, Vol 52 (8): 1123-1136, 2012. 


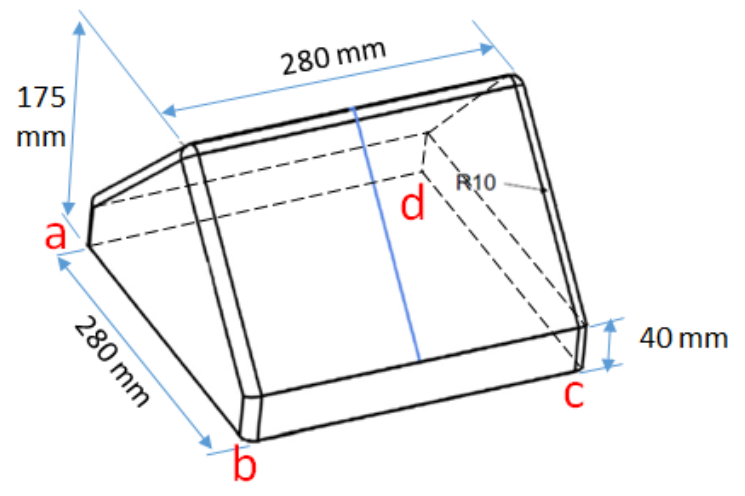

Figure $1:$ Punch dimensions

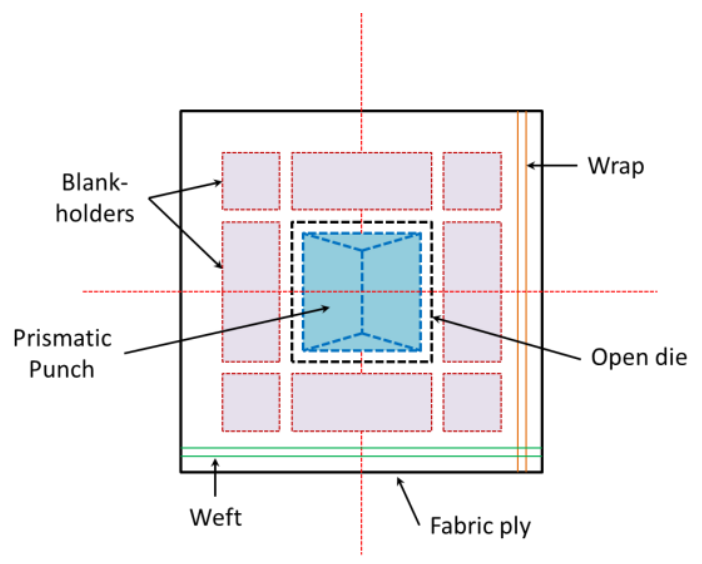

(a) Configuration 1

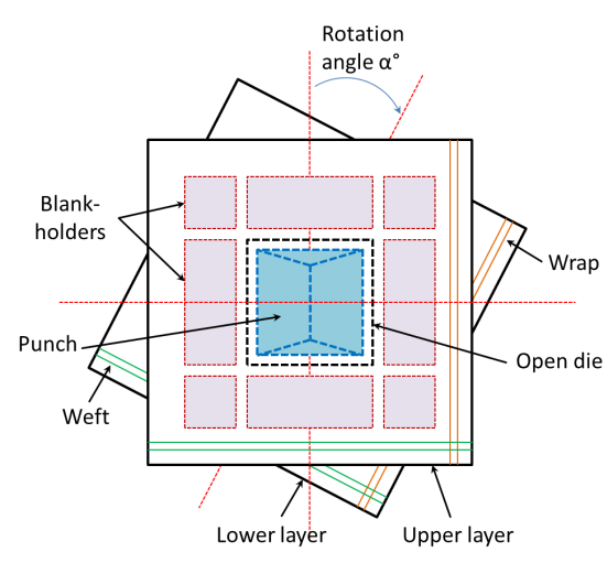

(b) Configuration 2

Figure 2 : Initial positioning of the fabric for the two draping configurations 


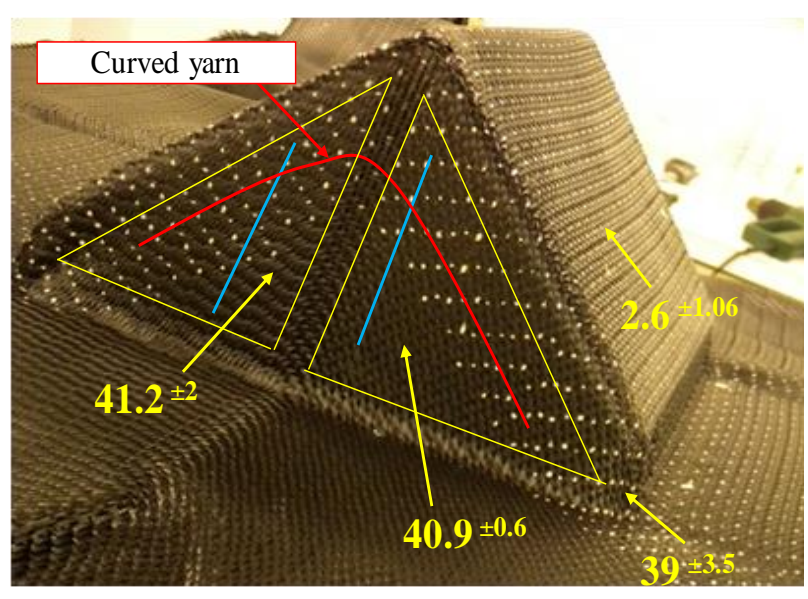

(a) Monolayer preform at $0^{\circ}$

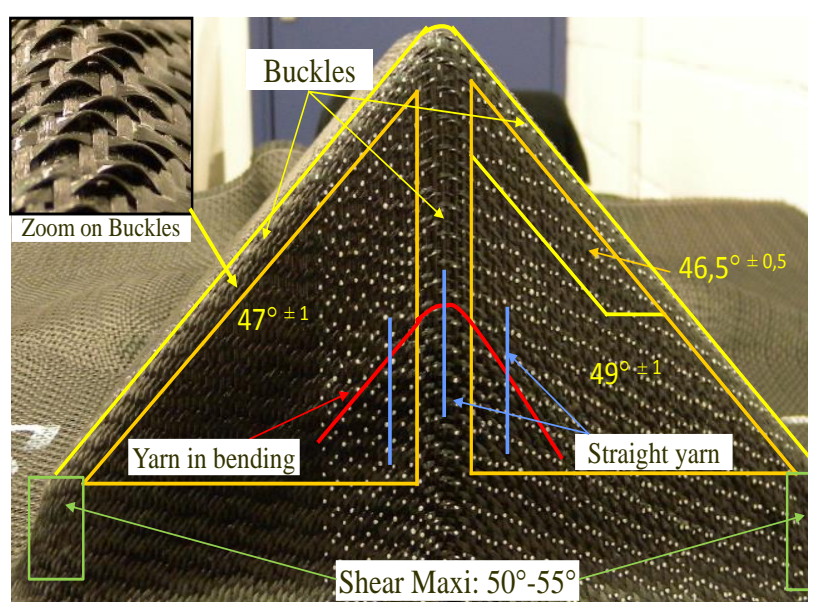

(b) Two-layer preform $0^{\circ} / 0^{\circ}$

Figure 3 : Preforms at reference configuration: at $0^{\circ}$ and at $0^{\circ} / 0^{\circ}$
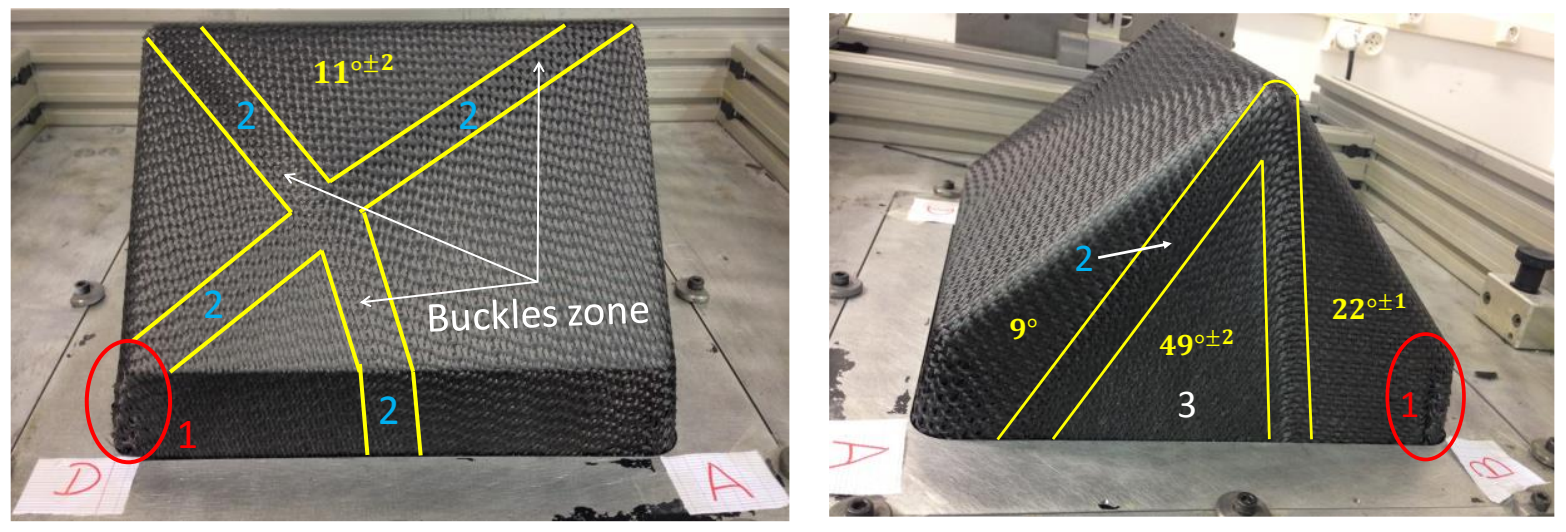

Figure 4 : Monolayer preform at $30^{\circ}$ 

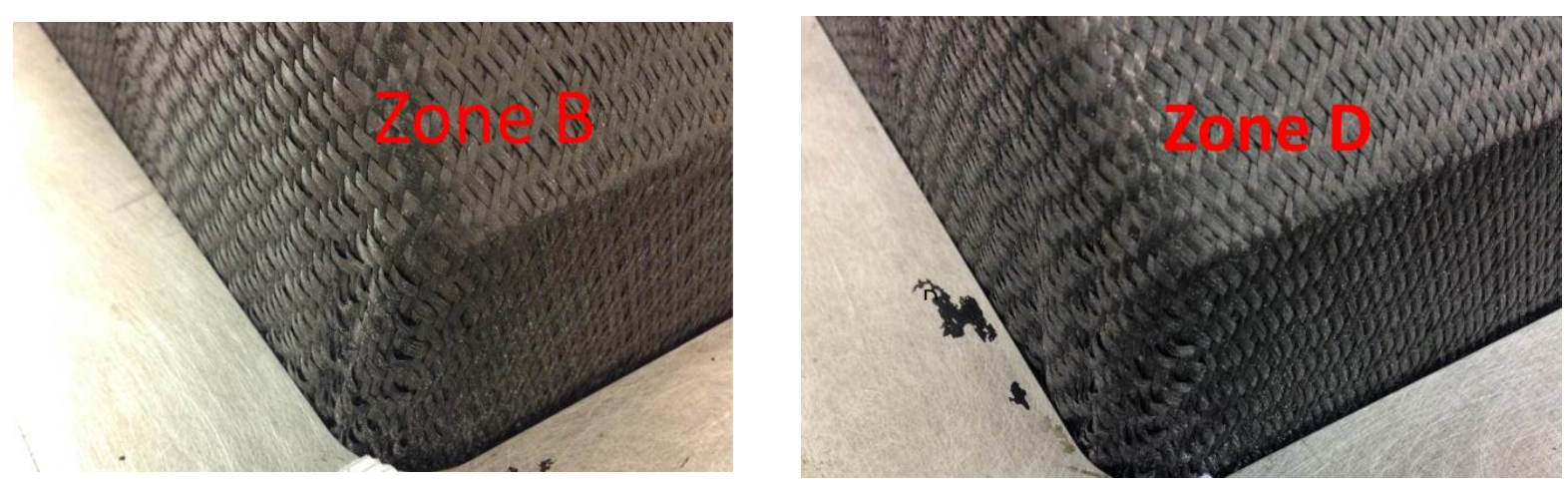

Figure 5 : Quality preform with pressure increasing, case of monolayer oriented at $30^{\circ}$
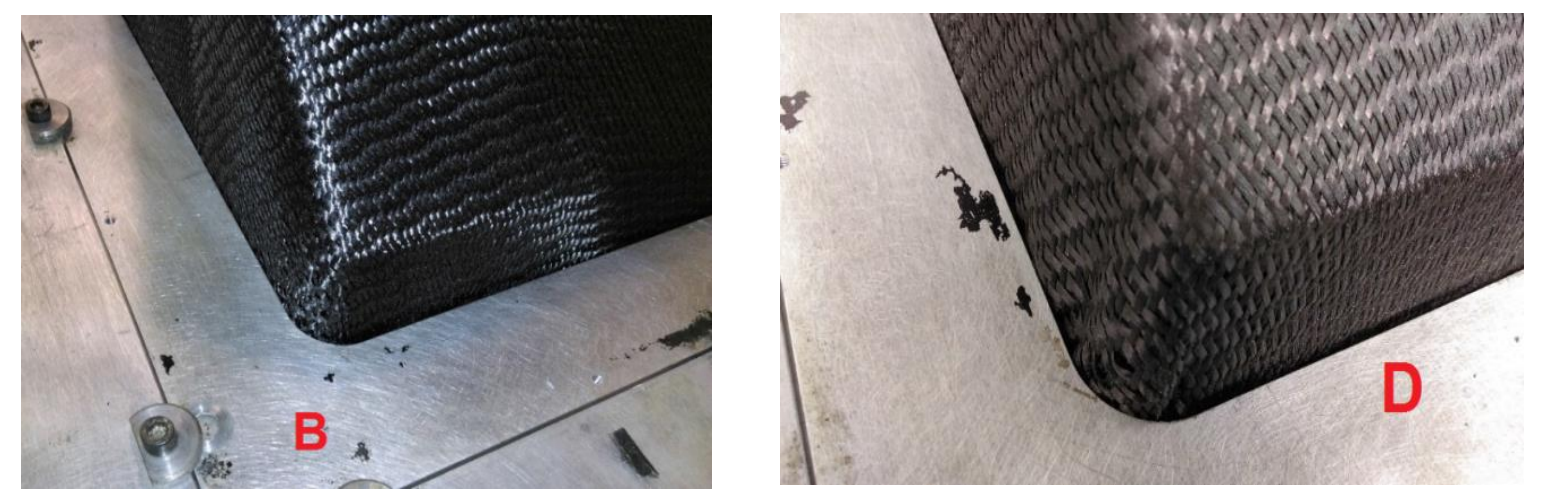

Figure 6: Quality preform with adapted blank-holders geometry, case of monolayer oriented at $30^{\circ}$ 

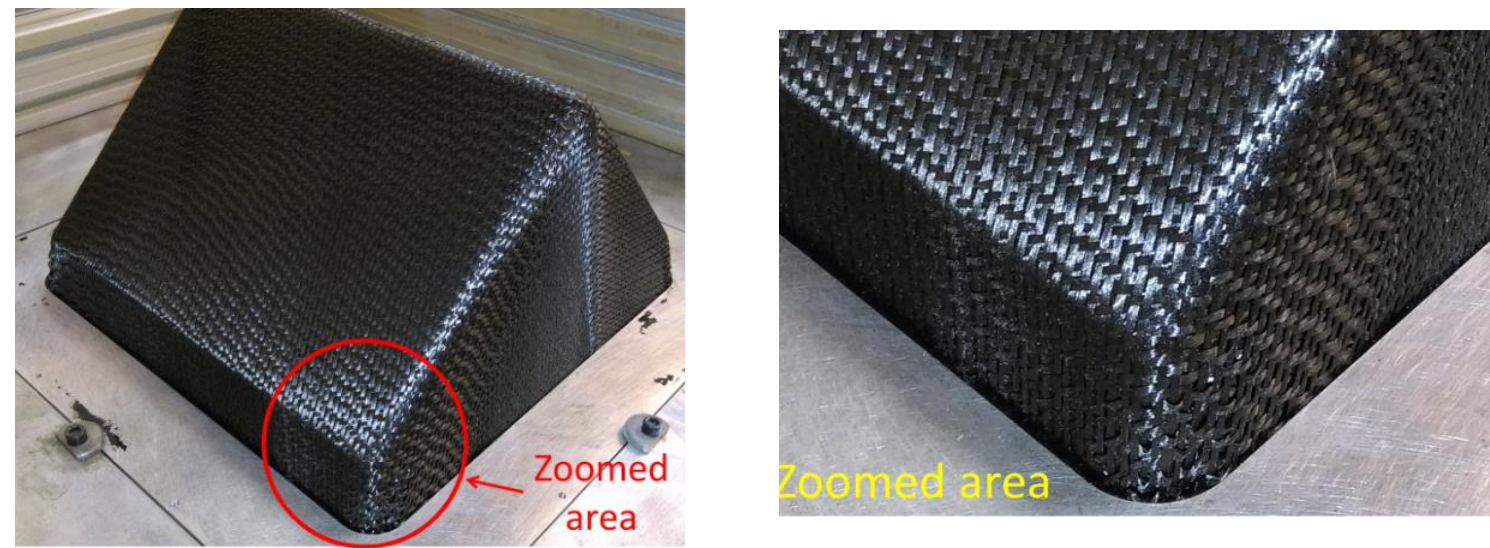

Figure 7 : Quality preform with pressure increasing and adapted blank-holders geometry

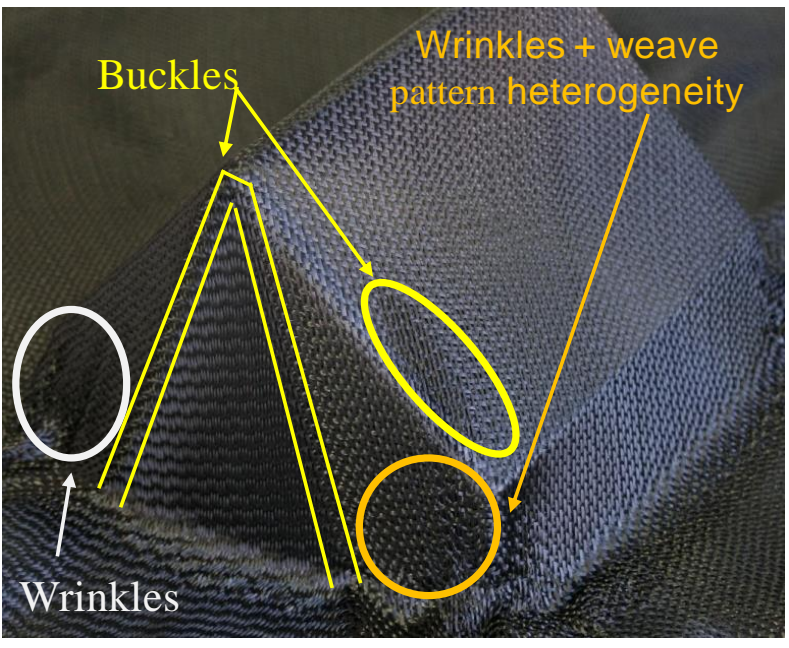

(a) Monolayer oriented at $45^{\circ}$

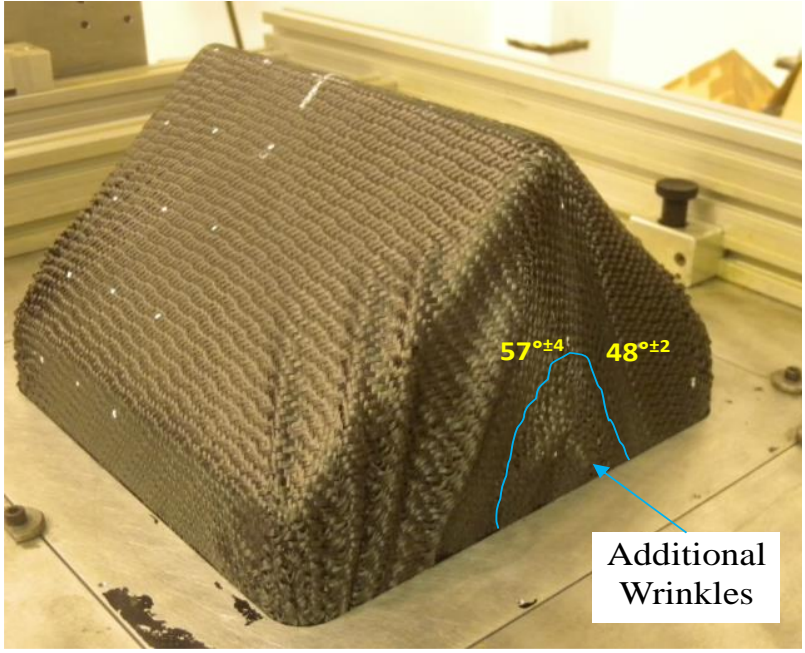

(b) Two-layer preform at $45^{\circ} \%^{\circ}$

Figure 8 : Preforms obtained with monolayer $\left(45^{\circ}\right)$ and tow-layers $\left(45 / 0^{\circ}\right)$ with initial process parameters 


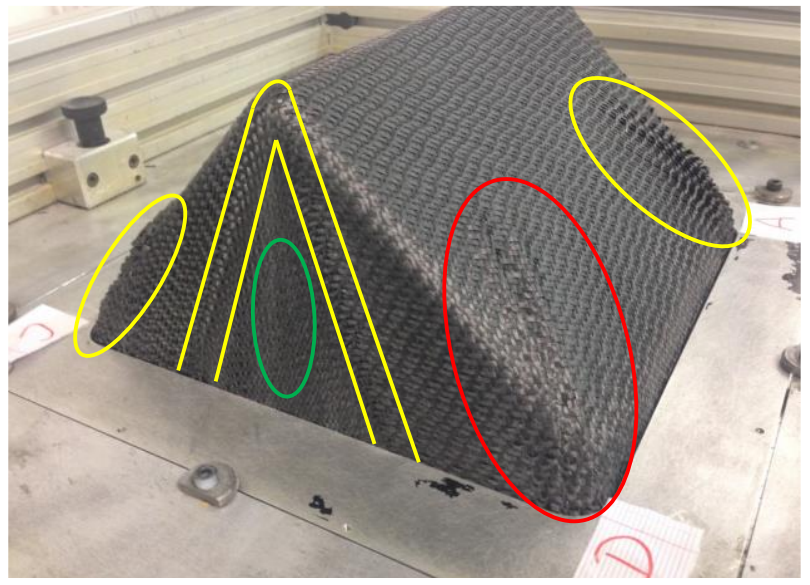

( a ) External layer, oriented at $45^{\circ}$

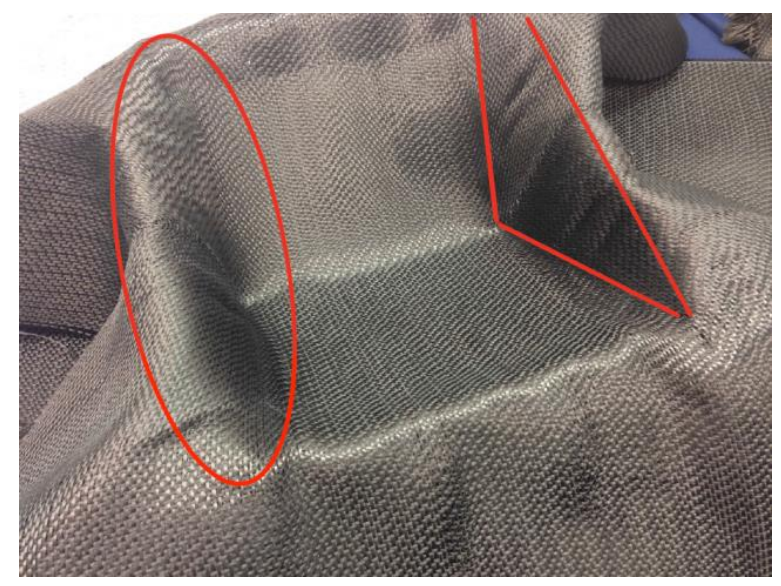

( b ) Internal layer at $0^{\circ}$

- $* * * * * * * *$ Wrinkles zone at B\&D corners and in interne layer

- $* * * * * * * *$ Buckles zones

- $* * * * * * * *$ Zone of an important shear without wrinkles

Figure $9: 45^{\circ} / 0^{\circ}$ defects after using of new blank holder geometry
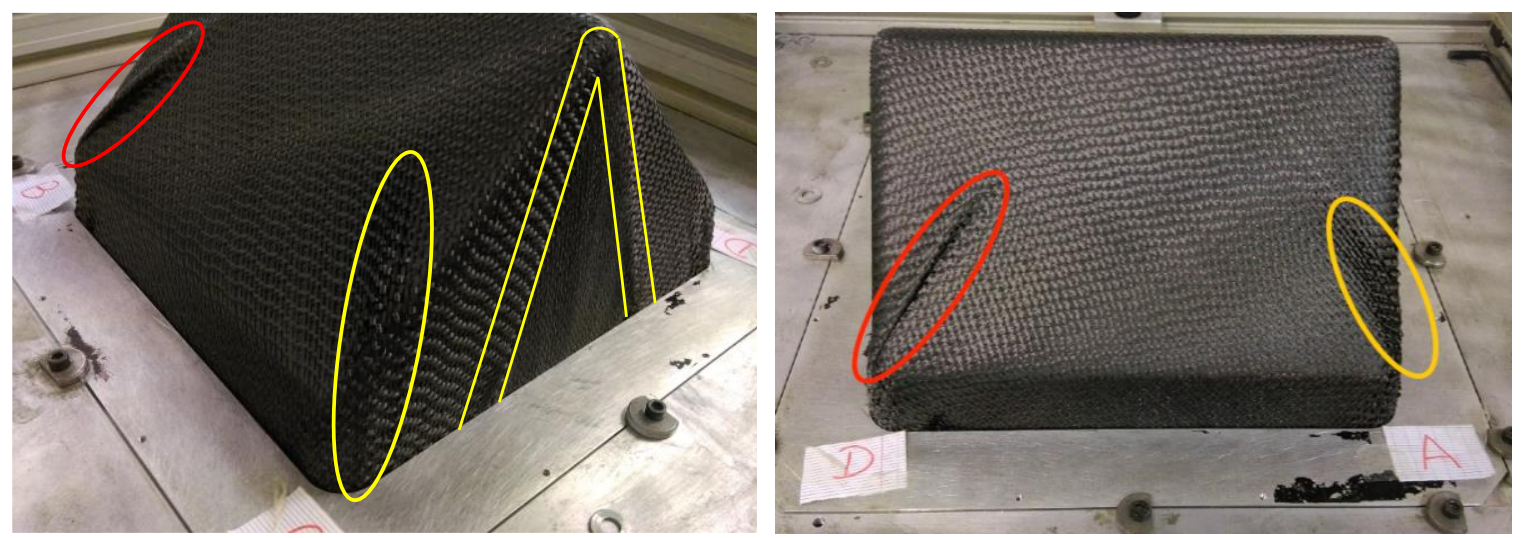

- $* * * * * * * *$ Wrinkles zone of light amplitude than previous test.

- $* * * * * * * *$ Buckles zone of light amplitude than previous test

Figure $10: 45^{\circ} / 0^{\circ}$ defects after combining of new blank holder geometry and pressure increasing 


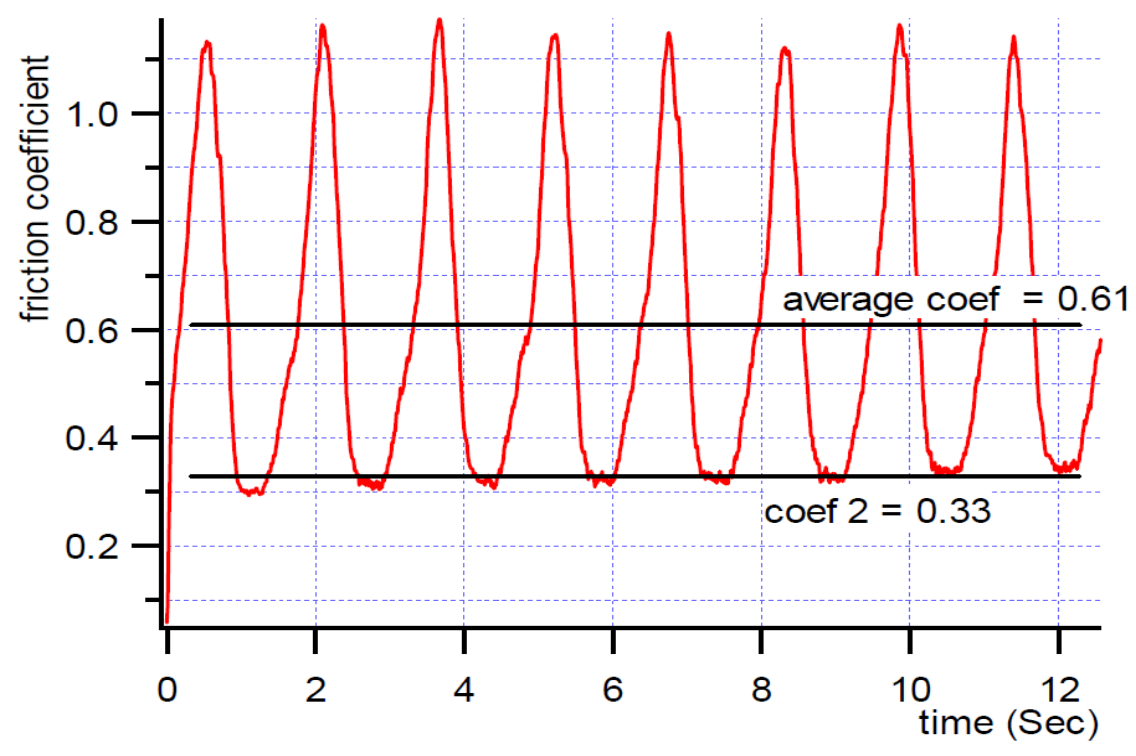

Figure 11 : Evolution of the ply/ply friction coefficient for the G1151® interlock fabric

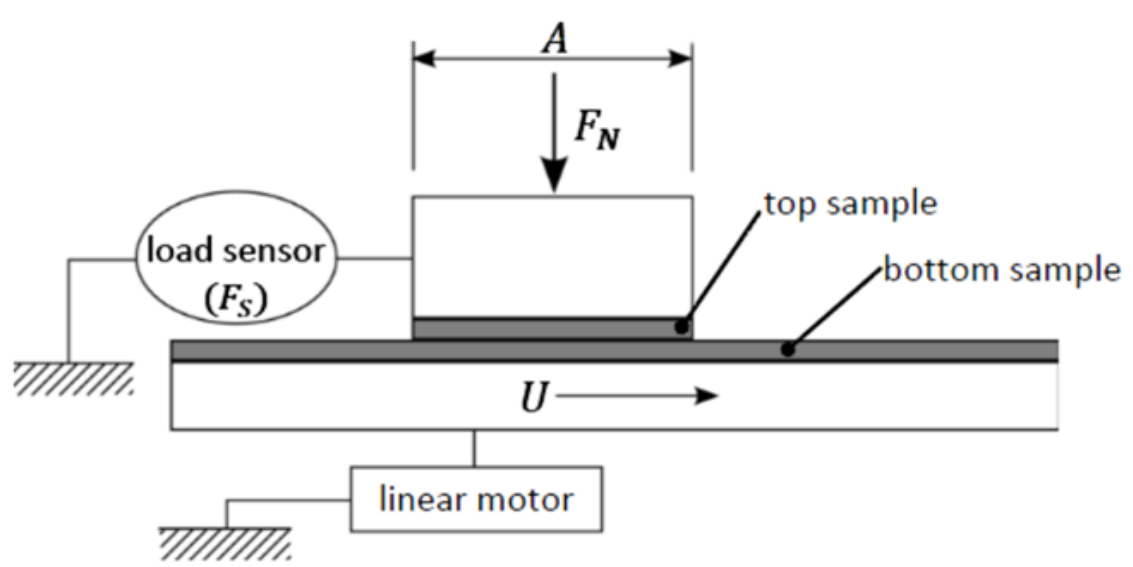

Figure 12 : Friction bench principle 


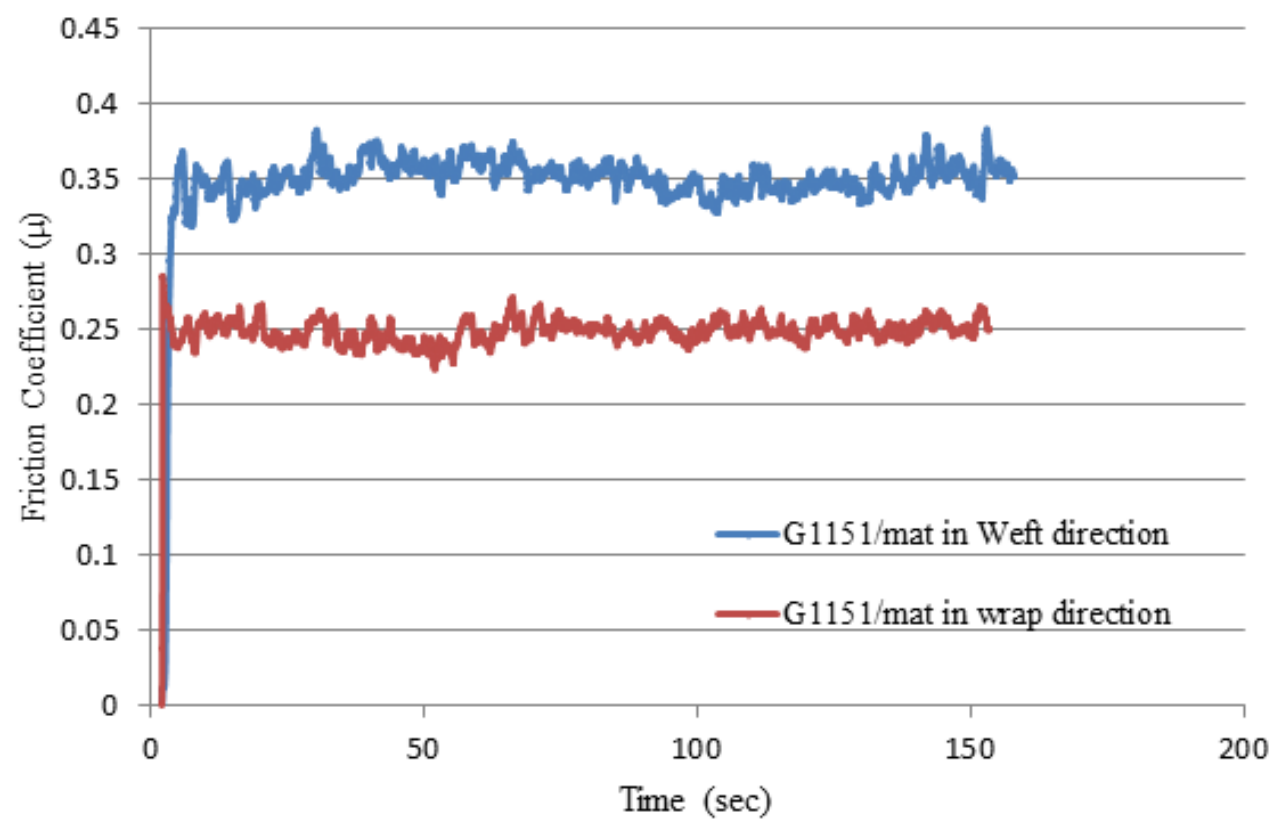

Figure 13 : Fabric/mat friction behaviors according to wrap and weft directions

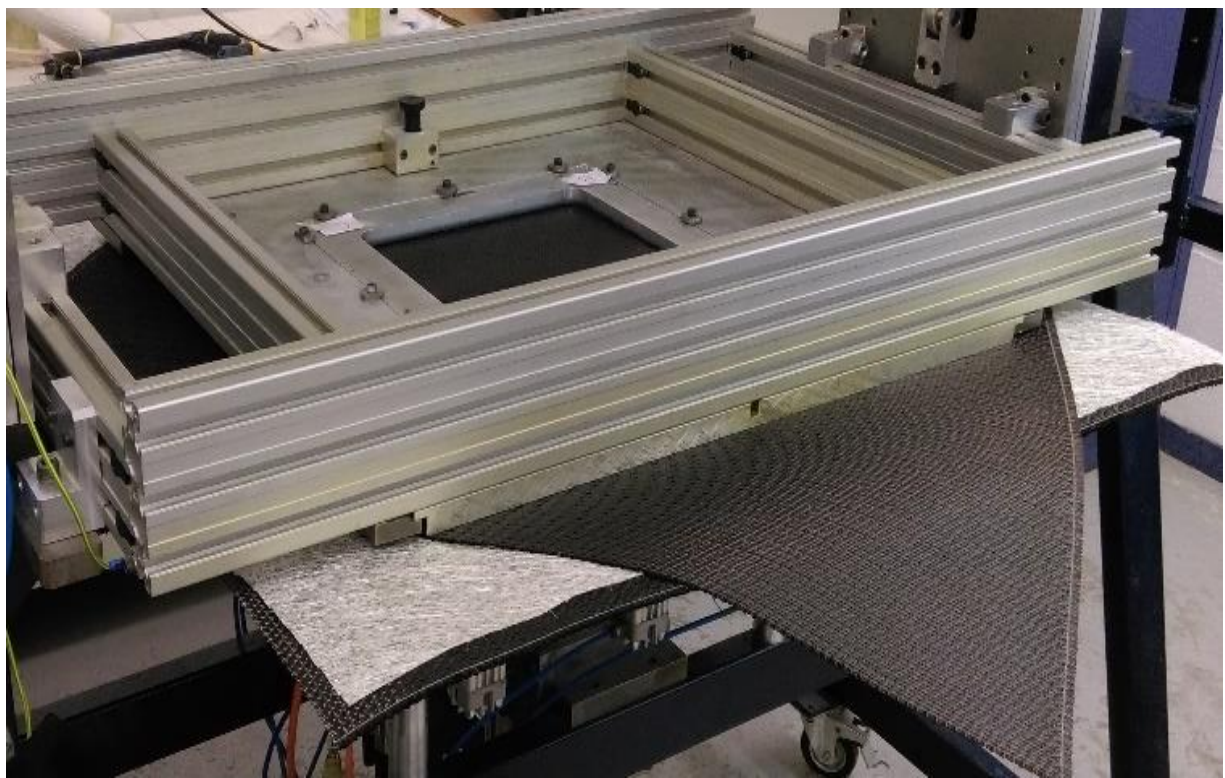

Figure 14 : Configuration of two layer preforming $\left(45^{\circ} / 0^{\circ}\right)$ with mat inserting. 

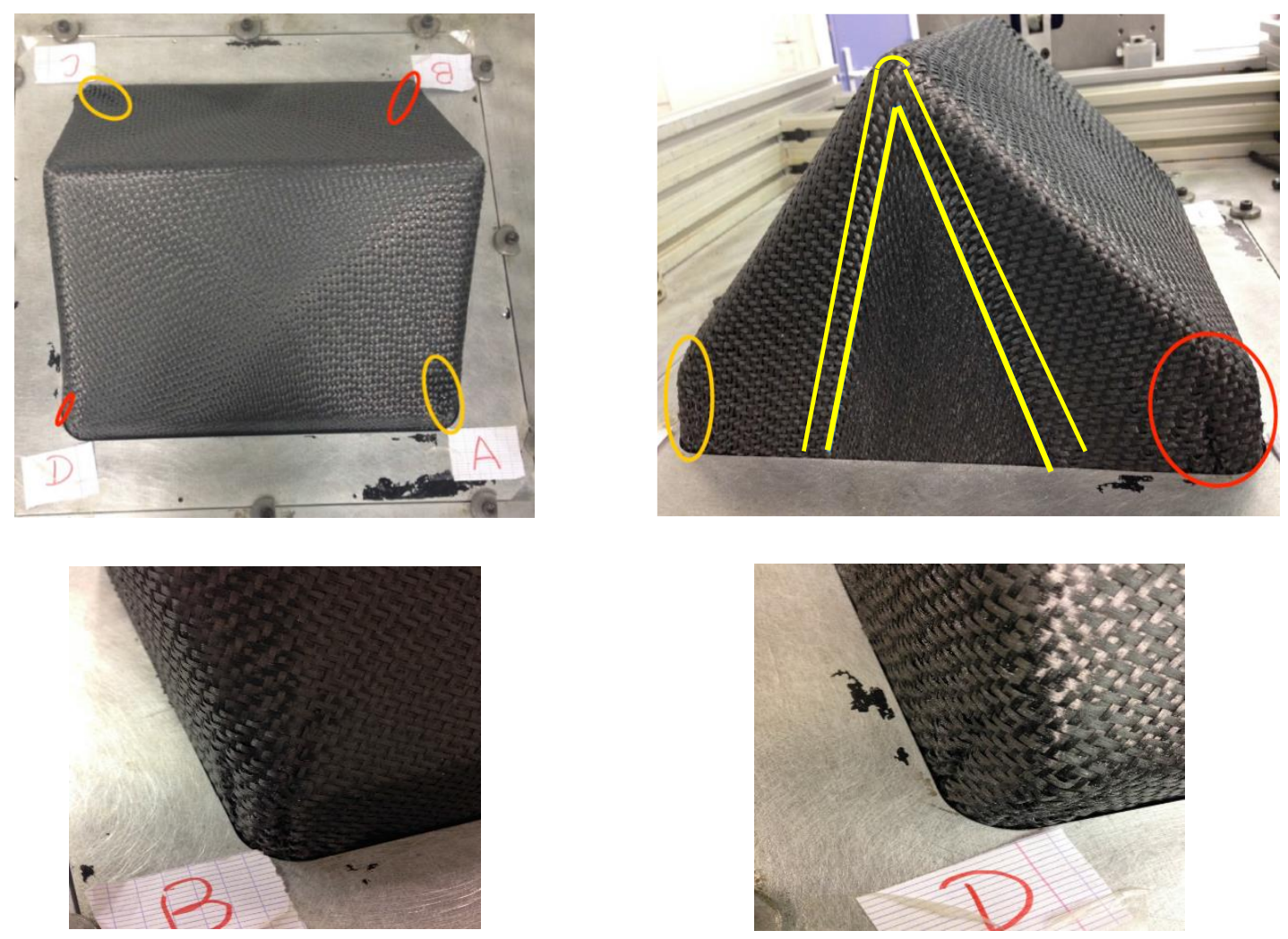

- $* * * * * * * *$ Wrinkles of light amplitude in comparison with the previous test

- $* * * * * * * *$ Buckles of light amplitude in comparison with the previous test

- No wrinkles appearance on the internal layer

Figure $15: 45^{\circ} / 0^{\circ}$ defects after combining of the three solutions: new holder-blacks geometry, pressure increasing and mat insertion. 


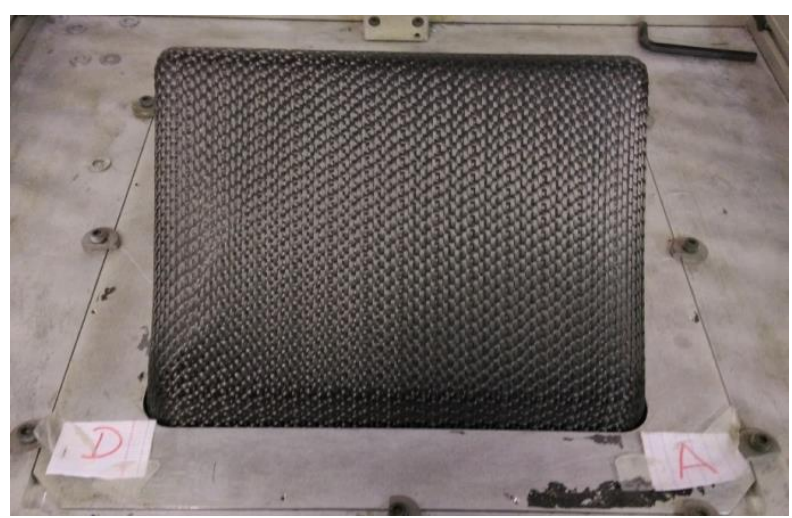

Overview without defects from A\&D corners side

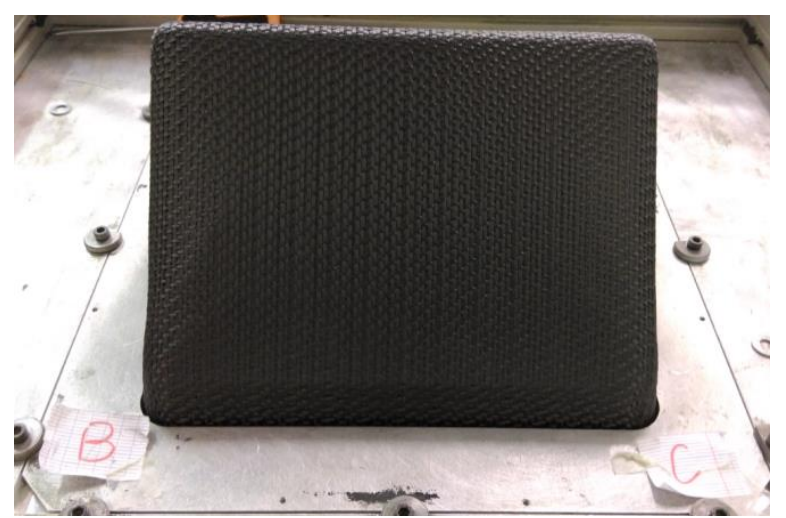

Overview without defects from B\&C corners side

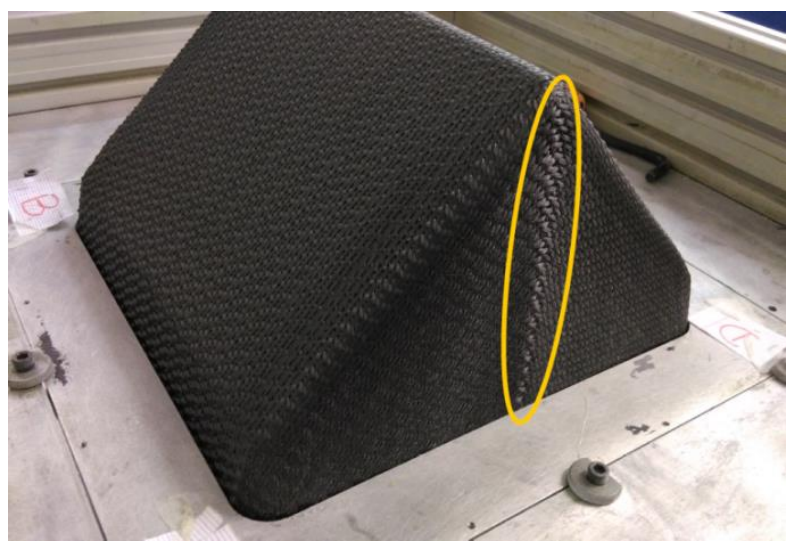

Zone of light buckles on the preform triangular area

Figure 16 : Complete disappearance of wrinkles defect when combining the four solutions: new blanks-holders geometry, optimal pressure value, using of mat layer and laying of the oriented layer below the non-oriented one. 


\begin{tabular}{|c|c|}
\hline Applied weight $[\mathrm{kg}]$ & 1,631 \\
\hline Contact section $\left[\mathrm{mm}^{2}\right]$ & 1600 \\
\hline Applied pressure (bars) & 0,1 \\
\hline Displacement velocity $(\mathrm{mm} / \mathrm{s})$ & 1 \\
\hline
\end{tabular}

Table 1: Experimental condition of friction tests

\begin{tabular}{|c|c|c|c|}
\hline Improvement solution & $\underline{\text { Wrinkles }}$ & $\underline{\text { Buckles }}$ & Global quality \\
\hline Two layers in initial configuration $45^{\circ} / 0^{\circ}$ & -- & - & -4 \\
\hline Pressure increasing & -- & - & -3 \\
\hline New blanks-holders geometry (rectangular form) & - & - & -2 \\
\hline Intermediate Mat insertion & ++ & + & +3 \\
\hline Pressure decreasing and new blanks-holder geometry & +++ & + & +4 \\
\hline $\begin{array}{c}\text { Pressure decreasing, new blanks-holders geometry and } \\
\text { intermediate mat }\end{array}$ & ++++ & + & +5 \\
\hline $\begin{array}{c}\text { Pressure decreasing, new blanks-holders geometry, } \\
\text { intermediate mat and } 0^{\circ} / 45^{\circ} \text { stacking sequence }\end{array}$ & ++++ & ++ & +6 \\
\hline
\end{tabular}

Table 2: Classification of the process parameters effect and their influence on the preform quality. 